\title{
On the Oxidation of Ammonia in Sea Water.
}

\author{
By
}

\section{G. P. Darnell-Smith, B.Sc., F.C.S.}

WHILST working at the Laboratory this summer on the function of iodine in Algæ, it was suggested to me by the Director that I should study the influence of Algæ on the ammonia in sea water. I here tender my thanks to Mr. E. J. Bles for his kind advice and assistance.

Before commencing experiments with Algæ the effect of keeping sea water in the light and in the dark was tried. Neither daylight nor darkness appears to have any effect on the amount of ammonia in the water. Thus-

Sea water containing . . $\quad .002$ grm. $\mathrm{NH}_{3}$ per 100 litres, After standing in the dark twentyfour hours contained . . . 0025

After standing in the dark fortyeight hours contained . . 002

Sea water containing . . . 001 " ,

After standing in the light eight hours contained

After standing in the light sixteen hours contained . . . 001

After a few days, however, whether standing in daylight or darkness, ammonia is produced by the decomposition of organic matter.

In order to test the efficiency of Algæ in oxidising the ammonia, sea water which had been in an inverted bell-jar seven days, with a fair quantity of Ulva, moderately illuminated, was analysed.

It contained

After being placed in the window twenty-four hours it contained After being placed in the window forty-eight hours it contained • • 009 , •0376 grm. $\mathrm{NH}_{3}$ per 100 litres. $\cdot 010$ , $\quad$, 
This rapid reduction of ammonia is probably due to the oxygen given off by the Ulva. To check this conclusion, water containing $\cdot 008$ grm. $\mathrm{NH}_{3}$ per 100 litres was placed in a bell-jar in the dark and a quantity of Ulva placed in it.

After twenty hours it contained . $\cdot 008$ grm. $\mathrm{NH}_{3}$ per 100 litres. After forty $\cdot 008$

Thus when assimilation was not proceeding the quantity of ammonia remained stationary. Decomposition then commenced, for-

After standing in the dark sixty-four

hours it contained

After standing in the dark eighty-

eight hours it contained

.012 grm. $\mathrm{NH}_{3}$ per 100 litres.

The jar was now placed in the window, and after standing there fortyeight hours it contained $\cdot 007 \mathrm{grm} . \mathrm{NH}_{3}$ per 100 litres. That the reduction of ammonia in sea water by Ulva depends upon the assimilation of the latter is further shown by the following experiments. Water, into which some Ulva had been put, had stood seven days in a position moderately illuminated.

It contained . . . . 037 grm. $\mathrm{NH}_{3}$ per 100 litres.

After standing in the window twenty-

four hours it contained . $\quad . \quad 009$

After standing in the window forty-

eight hours it contained . . $\cdot 010$

After standing in the window

seventy-two hours it contained .

$\cdot 015$

The available carbon dioxide had apparently been used up after the first twenty-four hours, and the plant was unable then to keep down the ammonia. A small quantity of carbon dioxide was now blown through the water, and after twelve hours it contained $\cdot 009$ grm. $\mathrm{NH}_{3}$ per 100 litres. A further quantity of carbon dioxide was blown through overnight, and after standing seven hours in daylight the water contained $\cdot 006$ grm. $\mathrm{NH}_{3}$ per 100 litres. That the reduction in the amount of ammonia was not due to the agitation of the water is shown by the following experiment. Water containing much ammonia was placed with Ulva in bright sunshine.

It contained at the commencement $\cdot 009$ grm. $\mathrm{NH}_{3}$ per 100 litres;

$\begin{array}{llll}\prime & \text { after five hours } & \cdot 003 & \text {, } \\ \text { after forty-one hours } & \cdot 006 \quad,\end{array}$

showing the same series of changes as in the previous experiment. Carbonic acid gas was now blown through it, and it was still found 
to contain 006 grm. $\mathrm{NH}_{3}$ per 100 litres. After standing one night and six hours in daylight, however, it contained 002 grm. $\mathrm{NH}_{3}$ per 100 litres. The preceding experiments show that when Ulva is assimilating rapidly and oxygen is given off, the ammonia in sea water is very quickly reduced. The amount of carbonic acid gas, however, available for purposes of assimilation is not clear ; from the "Challenger" Reports there does not appear to be any free carbonic acid gas in sea water, and Algæ, therefore, must depend upon that which is in a state of "loose" chemical combination.

An experiment was now made to test the rapidity of action of a current of air blown through the water. A current of air at the rate of 400 c.c. per minute was blown through sea water which contained-

At the commencement $\cdot 030$ grm. $\mathrm{NH}_{3}$ per 100 litres.

After five hours $\quad .023$

After twenty-six hours $\cdot 013$

After fifty hours $\quad 008$

",

A second experiment gave similar results, and it appears, therefore, that the oxygen given off by Algæ is very much more efficacious than that of the atmosphere, which is probably due to its being in the nascent condition. 